\title{
PERCEPÇÃO DE ALUNOS DA EAD DA UNIVERSIDADE DE TAUBATÉ QUANTO ÀS MUDANÇAS REALIZADAS NO INSTRUMENTO DE AVALIAÇÃO PRESENCIAL
}

TAUBATÉ/SP MAIO/2018

\author{
ISABEL ROSÂNGELA DOS SANTOS - UNITAU - isabel.eadunitau@gmail.com \\ MÁRCIA REGINA DE OLIVEIRA - UNITAU - moliveira.ead@gmail.com \\ PATRÍCIA ORTIZ MONTEIRO - UNITAU - patyortizmonteiro@terra.com.br \\ ROSANA GIOVANNI PIRES - UNITAU - rosanagiovanni.pires@gmail.com \\ SUSANA APARECIDA DA VEIGA - UNITAU - susana.veiga.ead@gmail.com
}

\author{
Tipo: Relato de Experiência Inovadora (EI) \\ Categoria: Pesquisa e Avaliação \\ Setor Educacional: EDUCAÇÃO SUPERIOR
}

\begin{abstract}
RESUMO
A legislação exige momentos presenciais de avaliação para programas de educação a distância e, inclusive, destaca que essa avaliação deve prevalecer sobre aquela realizada a distância. Este trabalho tem como objetivo analisar a percepção de alunos quanto às mudanças realizadas a partir de janeiro de 2018 nos instrumentos de avaliação presencial dos cursos a distância da Universidade de Taubaté. Como método de análise, foi utilizada uma abordagem qualitativa, com aplicação de um questionário estruturado a acadêmicos de alguns dos cursos de graduação oferecidos pela IES. Os resultados demonstraram haver entre os alunos um alto grau de satisfação quanto às mudanças, especialmente no que se refere ao fato de que as atividades realizadas no ambiente virtual terão um peso muito próximo ao das notas obtidas no instrumento de avaliação presencial; dessarte, o conhecimento adquirido ao longo da disciplina cursada poderá ser melhor avaliado.
\end{abstract}

Palavras-chave: Educação a Distância. Avaliação presencial na EAD.

\section{AGRADECIMENTOS}

A PRESENTE PESQUISA FAZ PARTE DAS ATIVIDADES DESENVOLVIDAS PELO NÚCLEO DE ESTUDOS E PESQUISAS INTERDISCIPLINARES EM SABERES E PRÁTICAS EM EDUCAÇÃO À DISTÂNCIA DO NEAD/UNIVERSIDADE DE TAUBATÉ. 


\section{Introdução}

O ato de avaliar é intrínseco à natureza humana. De modo geral, avaliar significa comparar as características de algo ou alguém com aquilo que é esperado, padronizado, definido. Dessa forma, podem-se avaliar aprendizagem dos alunos, projetos, programas, instituições, o estado de saúde de um indivíduo, entre outros (NUNES, 2010).

Ainda segundo Nunes (2010), a avaliação, antes de tudo, deve representar uma tomada de decisão, não devendo servir apenas para apontar o que está errado em relação ao que está sendo avaliado, mas também para retroalimentar o processo de planejamento, a fim de que as falhas possam ser consertadas ou pelo menos minimizadas.

A avaliação é um tema que desperta um imenso debate independentemente da modalidade de educação, seja presencial, semipresencial ou a distância. Vários fantasmas que assombram a avaliação na educação presencial ganham ainda mais força na educação a distância, como a cópia de trabalhos entre colegas ("cola"), cópia de trabalhos de fontes diversas e autoria de trabalho; ou seja, como garantir que quem entregou o trabalho foi quem realmente o fez? (NUNES, p.276-277, 2010).

Segundo Otsuka e Rocha (2002), na EAD a avaliação precisa ainda enfrentar outros desafios, além daqueles normalmente encontrados no processo de ensinoaprendizagem, e isso se deve às características peculiares dessa modalidade. A avaliação, quando realizada a distância, é mais complexa, por não termos o feedback das interações face a face, as quais permitiriam uma avaliação informal da aprendizagem do aluno. Os autores ainda destacam outro problema na avaliação quando feita a distância: como podemos garantir que quem está se submetendo à avaliação é realmente quem diz ser?

Por outro lado, a avaliação a distância mediada por computador oferece diversas vantagens, como distribuição fácil e barata, simplicidade e rapidez das atualizações, grande interatividade possibilitada pelos mecanismos de comunicação, facilidade para prover feedback, além do registro das interações para posterior análise (OTSUKA, ROCHA, 2002).

É importante destacar que, quando nos referimos à avaliação de aprendizagem em cursos a distância, devemos considerar: o projeto pedagógico do curso, se há ou não tutoria, se existe tutoria presencial, quais as tecnologias de informação e comunicação utilizadas, o ambiente virtual de aprendizagem e suas ferramentas avaliativas, entre tantas outras características que podem ser particulares de cada projeto e instituição.

Ciente da importância desta área para a aprendizagem dos estudantes e tendo em vista a crescente demanda de cursos, o Núcleo de Educação a Distância - NEAD - da Universidade de Taubaté criou, em 2016, um Grupo de trabalho na área de Avaliação da 
Aprendizagem, chamado de GT de Avaliação. Esse grupo, cujo objetivo inicial era apresentar e discutir técnicas para elaboração dos instrumentos de avaliação da aprendizagem, presencial e a distância, deveria, na sequência, criar estratégias e ações visando à formação dos professores nessa temática e à análise dos instrumentos de avaliação por eles elaborados, após terem recebido a tal formação.

A fim de garantir o atendimento aos critérios pedagógicos e metodológicos, a EAD Unitau adotou uma metodologia própria, descrita e documentada, para desenvolver os instrumentos de avaliação. Desde então, é a partir dos pressupostos contidos nesse documento que o GT de Avaliação vem orientando e capacitando os professores para a elaboração de instrumentos de avaliação que considerem os níveis de complexidade para a construção do conhecimento. Com igual rigor, o GT de Avaliação segue analisando os diversos materiais elaborados pelos professores que foram preparados para atuar em conformidade com a nova metodologia no que tange aos instrumentos de avaliação.

Em janeiro de 2018, por decisão do NEAD, após estudos e discussões da equipe de professores, mediados pelos que compõem o GT, o instrumento de avaliação presencial dos cursos EAD da Universidade de Taubaté passou a ser composto apenas por questões objetivas.

O presente trabalho de pesquisa tem como objetivo analisar a percepção dos alunos em relação a essa mudança, tendo em vista que os dados obtidos poderão no futuro contribuir para se mensurar os avanços qualitativos na aprendizagem.

\section{A Avaliação Presencial em EAD}

Para Gatti (2003, p. 99), é imprescindível pensar a avaliação como "uma atividade contínua e integrada às atividades de ensino, algo que é decorrente destas atividades, inerente a elas e a seu serviço". Ao professor compete a criação e verificação da utilidade de diferentes atividades que possibilitem avaliar os "processos de aquisição de conhecimentos e desenvolvimento de atitudes, de formas de estudo e trabalho, individual ou coletivamente".

Um dos maiores desafios em cursos a distância reside na forma de como se proceder o ato avaliativo fazendo uso dos instrumentos encontrados em Ambiente Virtual de Aprendizagem, sobretudo nas discussões do fórum de debates ou nos chats, uma vez que a análise nesses recursos é considerada como subjetiva. Destacamos aqui a importância da avaliação presencial - uma das exigências básicas estipuladas pelo MEC (Ministério da Educação), quando se trata de credenciamento e autorização de um curso 
a distância.

Segundo Maia et all (2005), a área de avaliação vem passando por uma mudança de paradigmas. Antes, era entendida apenas como um modelo de testes e exames, que valorizava a medição das quantidades aprendidas dos conhecimentos transmitidos. Agora, passou a ser vista como um modelo em que os aprendizes terão oportunidade de demonstrar o conhecimento que construíram, como o construíram, o que entendem a partir dele e o que podem fazer com ele. Ou seja, trata-se na atualidade de um modelo que valoriza as aprendizagens quantitativas e qualitativas no decorrer do próprio processo de aprendizagem.

Essa mudança de paradigma na educação implica a necessidade de alteração também na forma e no conceito da avaliação do aluno: esta deixa de ser um mero instrumento de avaliação de aprendizagem e passa a fazer parte do processo de ensino e aprendizagem. Avaliar pressupõe diagnosticar para observar comportamentos, atitudes, desempenhos, na expectativa de ao final do processo de aprendizagem analisar os dados apurados sob o olhar da revisão pedagógica, das mudanças necessárias para melhoria contínua da qualidade educacional (ROCHA, 2014).

Os critérios de avaliação devem ser elaborados no momento do planejamento do curso e depois explicitados aos alunos, para que eles tomem conhecimento de como serão avaliados desde o início do curso. Do ponto de vista prático, a educação a distância tem incorporado em seus processos avaliativos instrumentos que de certo modo fortalecem a associação entre seus pressupostos teóricos e a ação docente nas salas de aula virtuais e/ou presenciais. A avaliação a distância proporciona ao aluno um processo de aprendizagem menos dependente do professor e mais centrado no autoestudo. Isso permite uma maior flexibilidade para organizar as atividades, o que constitui uma das principais vantagens indicadas pelos alunos de cursos a distância (MAIA, MENDONÇA, GOES, 2005).

Resumidamente, a avaliação em EAD pode ser realizada de três formas principais:

a) Presencial: a avaliação é feita por meio de uma prova, na presença de uma pessoa responsável, com o intuito de garantir-lhe a legitimidade. As avaliações presenciais são realizadas com hora, data e local determinados;

b) A distância: com aplicação de testes on-line: a avaliação é feita por meio de mecanismos de testes on-line a serem respondidos e enviados posteriormente para 0 formador por meio de e-mail ou de formulários de envio. O tempo e o local nesta 
modalidade são de escolha do aluno, porém existem datas limites para serem entregues;

c) Avaliação ao longo do curso (contínua): a avaliação é feita de modo contínuo, baseada em componentes que forneçam subsídios para o formador avaliar seus aprendizes de modo processual. São exemplos: as atividades realizadas, os comentários postados, as participações em grupos de discussão e em chats, os fóruns, o envio de arquivos, o preenchimento de questionários, etc.

As avaliações presenciais, em geral, são realizadas de forma somativa, para verificar a aprendizagem dos pontos principais do conteúdo e determinar a promoção do aprendiz no final de um módulo ou curso (OTSUKA, ROCHA, 2002). A legislação exige momentos presenciais de avaliação para programas a distância e, inclusive, destaca que as notas dessa avaliação devem prevalecer sobre aquelas realizadas a distância. Essa obrigatoriedade, todavia, pode ser um impedimento para muitas pessoas que terão que se deslocar para os momentos de avaliação, fazendo com que a avaliação seja descontextualizada dos momentos de ensino-aprendizagem.

\footnotetext{
Há situações em que a presencialidade na avaliação é condição de aperfeiçoamento da aprendizagem; aquelas que envolvem algumas habilidades motora complexa, por exemplo. Nestas situações, a não previsão de avaliação ou de avaliação presenciais poderia ser tida como irresponsável; pois, se é imprescindível para a aprendizagem, torna-se um direito do aluno a ser respeitado (GONÇALVES, p.140, 1996).
}

Santos (2006) explica que quase sempre, para fins de avaliação da aprendizagem no Ensino Superior a Distância, a presencialidade é exigida, e que isso deriva do fato de que ainda não se conseguiu desenvolver uma forma de avaliar que supere a da avaliação presencial. Para o autor, uma situação de avaliação que, por exemplo, permite consultas a documentos de qualquer natureza, não tem por que ser presencial - no entanto, a lógica demonstra que, no Ensino a Distância, é muito complicado avaliar mudanças de comportamento, memorização e atitudes que não de forma presencial.

\section{A Avaliação Presencial na EAD Unitau}

O instrumento de avaliação presencial dos cursos a distância da Universidade de Taubaté passou por modificação no início do ano de 2018. Essa mudança foi planejada e preparada durante os anos de 2016 e 2017 pelo GT de Avaliação e pelos coordenadores de cada um dos cursos. Portanto, muitas reuniões e oficinas antecederam o momento de efetivar as mudanças. Até o final de 2017, as provas presenciais eram compostas por algumas questões objetivas (a quantidade poderia mudar de curso para curso) e uma ou duas questões dissertativas. É importante destacar que não havia uma padronização, ou regra, quanto à forma de elaboração 
dessas questões, tanto das objetivas quanto das dissertativas.

A partir de janeiro de 2018, o instrumento de avaliação presencial passou a ser composto apenas por questões objetivas, as quais devem seguir uma padronização, conforme matriz de referência construída anteriormente pelo GT de Avaliação. Essa matriz identifica modelos diferentes de questões, bem como os níveis de complexidade que as questões do instrumento de avaliação presencial devem conter.

As mudanças aconteceram também no percentual de participação da nota final de cada uma das disciplinas. Para a composição da nota final do aluno na disciplina, as avaliações presenciais representavam $60 \%$ da nota final do aluno. Após as tais mudanças, com o intuito de valorizar a avaliação contínua ao longo do desenvolvimento da disciplina, as avaliações presenciais passaram a representar $51 \%$ da nota final. Com isso, as atividades desenvolvidas pelos alunos no ambiente virtual ganharam um peso maior no cômputo final da nota.

\section{Metodologia}

O presente estudo - uma pesquisa com uma abordagem qualitativa - foi realizado com o objetivo de avaliar a percepção dos alunos em relação às mudanças realizadas no instrumento de avaliação presencial.

Para tanto, 89 alunos matriculados nos cursos das áreas de Ciências da Natureza e Matemática e Gestão e Negócios - matriculados e cursando disciplinas dos cursos pesquisados há pelo menos seis meses antes da mudança realizada no instrumento de avaliação - foram convidados a responder um questionário composto por questões sobre aspectos socioeconômicos do respondente e questões relacionadas às mudanças no instrumento de avaliação presencial, que lhes foi enviado por e-mail.

\section{Resultados e discussão}

Os Referenciais de qualidade para a educação superior a distância, estabelecidos pelo MEC (2007), destacam a importância de a avaliação ser formativa e ocorrer de forma presencial e a distância. Reafirmam ainda a obrigatoriedade de se observar que as avaliações presenciais preponderem sobre outras formas de avaliação.

A partir de um universo de 89 alunos matriculados nos cursos das áreas de Ciências da Natureza e Matemática e Gestão e Negócios, que receberam o questionário por e-mail, 47 alunos responderam-no e devolveram, totalizando 53\% da amostra inicial.

Dos 47 alunos, sujeitos da pesquisa, $77 \%$ são da área da Ciências da Natureza e 
Matemática e 23\%, da área de Gestão e Negócios; $64 \%$ são do sexo feminino e 36\%, do sexo masculino; $28 \%$ têm mais de 40 anos de idade; e $48 \%$ são casados.

Com relação à mudança no modelo do instrumento de avaliação presencial da EAD Unitau, que passou a ser composto somente por questões objetivas (em vez de trazer questões objetivas e dissertativas, como aconteceu até 2017), 41,3\% dos alunos consideram que a mudança foi boa (Figura 1).

Figura 1: Percepção dos alunos quanto à mudança no modelo do instrumento de avaliação presencial da EAD Unitau

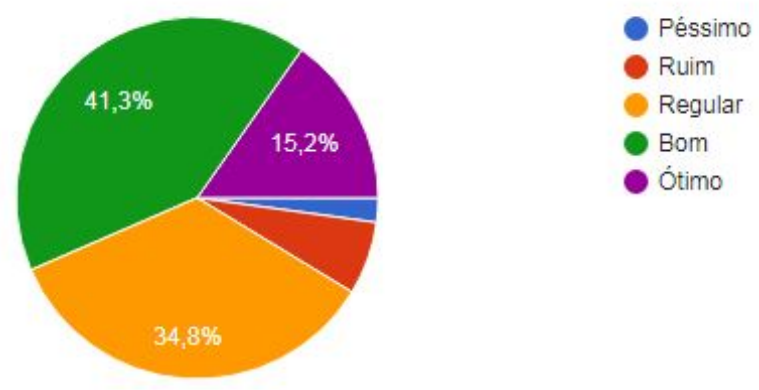

Fonte: Elaborado pelas autoras

A partir do ano de 2018, a pontuação do instrumento de avaliação presencial da EaD Unitau passou de 6,0 pontos para 5,1 pontos e a pontuação do instrumento de avaliação a distância (ambiente virtual) passou de 4,0 pontos para 4,9 pontos. Quanto à mudança na pontuação dos instrumentos de avaliação, 58,7\% dos alunos a consideraram boa e $28,3 \%$, ótima (Figura 2).

Figura 2: Percepção dos alunos quanto à mudança na pontuação do instrumento de avaliação presencial da EAD Unitau 


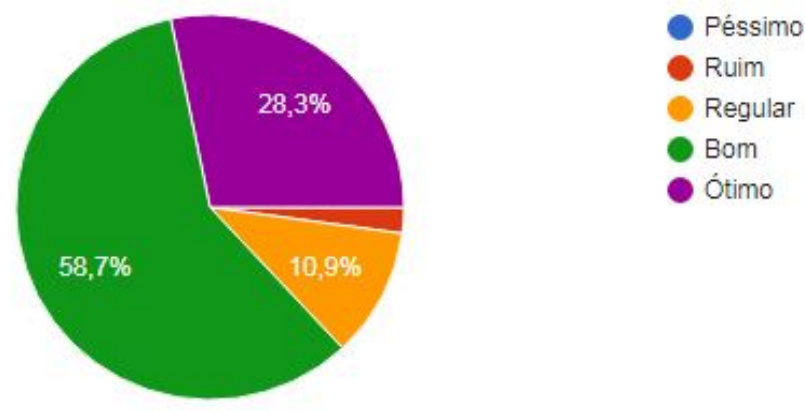

Fonte: Elaborado pelas autoras

Um dos objetivos da Instituição ao mudar os instrumentos de avaliação e suas respectivas pontuações era o de valorizar as atividades desenvolvidas pelos alunos da EAD Unitau no ambiente virtual (que passou de 4,0 para 4,9 pontos), e com isso promover a avaliação contínua do aluno. Com relação a esse questionamento, 54,3\% dos respondentes afirmaram que esse objetivo será alcançado totalmente (Figura 3).

Figura 3: Percepção dos alunos quanto ao objetivo da Instituição de valorizar as atividades desenvolvidas no ambiente virtual
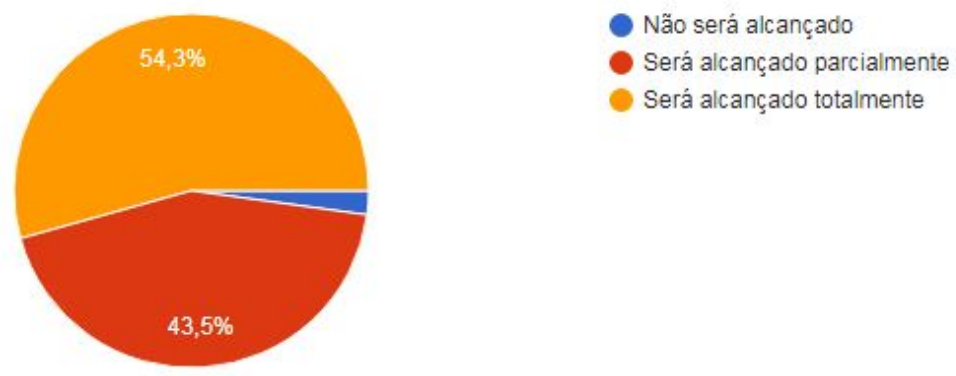

Fonte: Elaborado pelas autoras

Com relação à melhoria da possibilidade de avaliação do conhecimento adquirido pelo aluno, por meio da aplicação dos instrumentos de avaliação, 56,5\% dos respondentes concordam plenamente que o conhecimento será melhor avaliado (Figura 4).

Figura 4: Percepção dos alunos quanto à melhoria da avaliação do conhecimento adquirido 


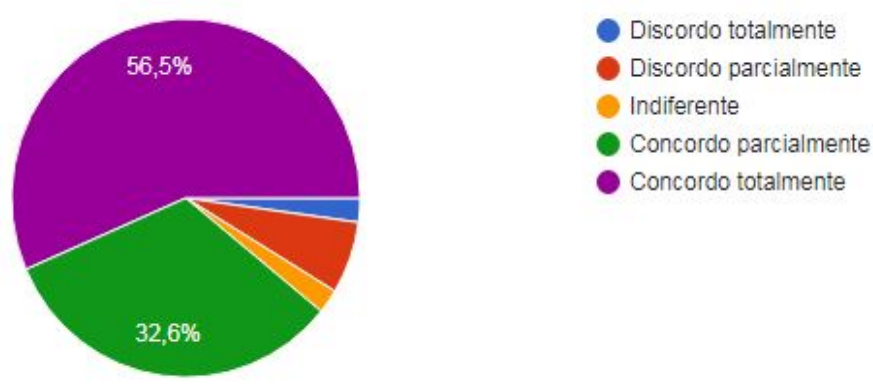

Fonte: Elaborado pelas autoras

É importante destacar que as avaliações presenciais são pautadas nos conteúdos mais relevantes da disciplina e tem como objetivo verificar a promoção do aprendizado do aluno no final do módulo.

\section{Conclusão}

O presente trabalho teve por objetivo analisar a percepção de estudantes de alguns cursos a distância da Universidade de Taubaté em relação às alterações realizadas no instrumento de avaliação presencial.

Os resultados da pesquisa, da qual participaram 47 respondentes, mostraram que $56,5 \%$ deles consideraram a mudança boa ou ótima. Quando questionados sobre a alteração na pontuação dos instrumentos de avaliação, o número de alunos que considerou a mudança como boa ou ótima subiu para $87 \%$.

A alteração nos instrumentos de avaliação da EAD Unitau implica que as notas obtidas pela resolução das atividades no ambiente virtual terão um peso muito próximo ao das notas obtidas no instrumento de avaliação presencial; $56,5 \%$ dos sujeitos da pesquisa acreditam que, dessa forma, o conhecimento adquirido ao longo da disciplina cursada poderá ser melhor avaliado.

Os números apresentados servem para comprovar que as mudanças realizadas até 0 momento foram aprovadas pelos alunos. Destacamos, porém, que as mudanças nos instrumentos de avaliação continuarão. A primeira etapa da mudança ocorreu no final do mês de janeiro de 2018, quando o instrumento de avaliação presencial passou a ser composto apenas por questões objetivas. A partir do mês de maio de 2018, iniciaram-se as mudanças nas atividades avaliativas do ambiente virtual. 


\section{Referências}

FAGANELLO, J.; REIS, E. dos; GUIMARÃES, M. I. P. Os instrumentos de avaliação da aprendizagem e a avaliação formativa em educação a distância. Disponível em: http://sistemas3.sead.ufscar.br/ojs/index.php/2016/article/view/1262

GATTI, B. A. O Professor e a Avaliação em Sala de Aula. Estudos em Avaliação Educacional, São Paulo, n. 27, jan-jun, 2003. Disponível em: $<$ http://abecin.org.br/data/documents/Gatti_Professor_avaliacao_sala_aula.pdf $>$ Acesso em: 01 mar. 2017.

GONÇALVES, C. T. F. Quem tem medo do ensino a distância?, in Revista Educação a Distância, n.ำ 7-8, INED/IBASE, 1996.

MAIA, M. C.; MENDONÇA, A. L.; GOES, P. Metodologia de Ensino e Avaliação de Aprendizagem. Disponível em $<$ http://www.abed.org.br/congresso2005/por/pdf/206tcc5.pdf $>$. Acesso em 22 de abr. de 2018.

NUNES, R. C. A Avaliação em Educação a Distância é Inovadora? - Uma Reflexão. $16^{\circ}$ Congresso Internacional Abed de Educação a Distância, Foz do Iguaçu, 2010. OTSUKA, J. L.; ROCHA, H. V. A caminho de um modelo de apoio à avaliação contínua. XXII Congresso da SBC. Florianópolis. Sociedade Brasileira de Computação, 15-19 julho, 2002.

SANTOS, J. F. S. Avaliação no Ensino a Distância. Revista Iberoamericana de Educación, 2006.

PERRENOUD, P. Avaliação: da excelência à regulação das aprendizagens. Entre duas lógicas. Porto Alegre: Artmed, 1998.

PRETI, O. (org.) Educação a distância: uma prática mediadora e mediatizada, in "Educação a distância: inícios e indícios de um percurso". Cuiaba, UFMT, 1996.

ROCHA, E. F. Avaliação na EaD: estamos preparados para avaliar? Disponível em: $<$ http://www.abed.org.br/arquivos/Avaliacao_na_EaD_Enilton_Rocha.pdf $>$. Acesso em 24 de abr. de 2018. 